\title{
IMPORTÂNCIA DO DESENVOLVIMENTO DE ESTRATÉGIAS DE LEITURA PARA A APRENDIZAGEM DE ESPANHOL A DISTÂNCIA
}

\author{
J. M. MELLO' e R. S. GONÇALVES ${ }^{2}$ \\ ${ }^{1} \mathrm{e} 2 \mathrm{UAB} / \mathrm{IFRN}$ \\ janire_espanhol_ifrn@hotmail.com - rousi_g@hotmail.com
}

Artigo submetido em outubro/2011 e aceito em dezembro/2011

\section{RESUMO}

Na modalidade de ensino a distância em língua espanhola, observamos que os alunos apresentam em seus relatos dificuldades para compreender o material e em expor suas dúvidas, por não haver contato direto com os professores e toda a comunicação ser baseada em fóruns, caixas de textos das atividades e caixas de mensagens. Com base neste problema, resolvemos investigar o papel que a leitura e a escrita representam no processo de aprendizagem do ensino à distância em espanhol, através de informações dos próprios alunos do curso Licenciatura em Letras Espanhol, modalidade a distância, oferecido pelo IFRN/UAB. Foram utilizadas como

fontes para a coleta de dados a análise das postagens feitas pelos alunos na Plataforma Moodle, além das atividades enviadas pela autora. A partir da análise dos dados, constatouse que a leitura e a escrita, na modalidade EaD, adquirem papel fundamental para o processo de aprendizagem por estarem presentes em quase todos os momentos do curso e serem mediadoras da interação entre os professores, tutores e alunos, servindo como instrumentos que são utilizados para avaliação de desempenho, exposição de dificuldades, solução de dúvidas e problemas relacionados ao curso.

PALAVRAS-CHAVE: Leitura, Escrita, Espanhol.

\section{IMPORTANCIA DEL DESARROLLO DE ESTRATEGIAS DE LECTURA PARA EL APRENDIZAGE DEL ESPAÑOL}

\section{RESUMEN}

En la modalidad a distancia de la educación en español, observamos que los alumnos presentan en sus relatos dificultades para comprender el material y para exponer sus dudas, porque no hay contacto directo con los maestros y todas las comunicaciones son basadas en los foros, los cuadros de texto de las actividades y los cuadros de mensaje. Con base en este problema, decidimos investigar el papel que la lectura y la escritura representan en el proceso de aprendizaje de la educación a distancia en español, a partir de informaciones de los estudiantes de la Licenciatura em Letras Espanhol en la modalidad a distancia de IFRN/UAB. Fueron utilizadas como fuentes para la colecta de datos el análisis de las publicaciones hechas por los estudiantes en la plataforma Moodle, además de las actividades presentadas por la autora. A partir del análisis de datos, constatamos que la lectura y la escritura en el modo de educación a distancia, adquiere papel clave en el proceso de enseñanza y aprendizaje, está presente en casi todas las fases del curso y son mediadoras de la interacción entre profesores, tutores y estudiantes sirviendo como instrumentos que son utilizados para la evaluación del desempeño, problemas de exposición, preguntas y solucionar dudas relacionadas con el curso.

PALAVRAS-CHAVE: Lectura, Escritura, Español. 


\section{IMPORTÂNCIA DO DESENVOLVIMENTO DE ESTRATÉGIAS DE LEITURA PARA A APRENDIZAGEM DE ESPANHOL A DISTÂNCIA}

\section{INTRODUÇÃO}

Este estudo surgiu a partir de uma sugestão da professora responsável pela disciplina Língua Portuguesa do curso de licenciatura em Espanhol do IFRN. A mesma propôs quatro sub-temas que articularse-iam às áreas temáticas propostas para a Jornada Hispânica, entre os quais escolheu-se refletir sobre a Importância do processo de leitura e escrita para a aprendizagem de espanhol dos alunos da modalidade a distância.

Aceitei o desafio por acreditar que, partindo de uma investigação sobre como a comunicação flui entre os participantes do ambiente virtual, será possível encontrar formas de minimizar as dificuldades encontradas pelos alunos observados.

A transição do ensino presencial para o ensino a distância é um desafio e pode levar um tempo até que os alunos se adaptem. As diferenças são muitas e a modalidade a distância exige muito mais do aluno que deve ter uma postura autodidata, sendo disciplinado e automotivado. $\mathrm{O}$ trabalho apresenta uma relação entre a leitura, compreensão e interpretação do material das aulas com respostas da autora às atividades e as postagens dos outros alunos do polo de apoio de Natal, a fim de entender como as estratégias de leitura estão contribuindo para essa comunicação. Essas estratégias permitem que, no ato da leitura, o leitor possa selecionar, antecipar, inferir e verificar as informações contidas no texto para que se construa um sentido. São mecanismos que auxiliam o leitor a compreender e dar sentido ao texto.

Ao conhecer as características na comunicação entre professores/tutores e alunos, as causas poderão ser encontradas e possibilitarão a tomada de medidas que minimizem seus impactos e contribuam para um processo de aprendizagem mais eficiente.

O caminho é a análise da escrita de alguns alunos do pólo de Natal, observando a capacidade de expressar suas dúvidas e entendimento das respostas dadas às suas indagações, além de verificar meu próprio desempenho durante o semestre por meio das atividades por mim realizadas e enviadas para avaliação por meio da plataforma Moodle e com base no feedback dado pela professora e o tutor da disciplina de Língua Portuguesa, após a correção de cada atividade,

A utilização de estratégias de leitura no processo de aprendizagem envolve a ativação de conhecimentos que vão desde a compreensão da escrita até o conhecimento de mundo do leitor (GONÇALVES, 2010). Tomando como partida o desejo de contribuir para a melhoria do curso, um melhor aproveitamento das aulas e uma melhor interação entre professores, tutores e alunos, se faz necessário que os co-enunciadores busquem um ponto de equilíbrio. O escritor deve colocar-se no lugar do leitor ao produzir o texto, enquanto o leitor deve fazer uso das estratégias de leitura para ter uma melhor compreensão do que é lido atribuindo-lhe sentido.

Diante do exposto, tentarei encontrar respostas às minhas indagações através de análise do conteúdo inserido na plataforma Moodle, da minha experiência e trajetória dentro da modalidade a distância, identificando as dificuldades enfrentadas por mim e meus colegas de curso, numa tentativa de 
buscar soluções para o melhor desenvolvimento do processo de aprendizagem. Este trabalho apresenta uma abordagem parcial sobre leitura, escrita, modalidade a distância e desenvolvimento de estratégias de leitura, como essas estratégias auxiliam no aprendizado da língua espanhola e como os alunos do curso de licenciatura em língua espanhola do IFRN/UAB estão fazendo uso dessas estratégias, através de análise de suas postagens na plataforma. Este estudo propõe temas que poderão ser aprofundados em pesquisas posteriores, uma vez que não foi possível realizar uma investigação mais aprofundada e envolvendo todos os alunos do curso.

\section{LEITURA E ESCRITA EM EAD: FOCO NA INTERAÇÃO}

A escrita está presente em todos os momentos da nossa vida, seja em bilhetes, e-mails, placas, embalagens, e demais textos do nosso cotidiano. Existem muitas definições sobre o que é a escrita, para KOCH \& ELIAS (2009, p.32) "o modo pelo qual concebemos a escrita não se encontra dissociado do modo pelo qual entendemos a linguagem, o texto e o sujeito que escreve" assim, a escrita pode ser vista de três formas: foco na língua, foco no leitor e foco na interação.

Sobre a primeira forma, KOCH \& ELIAS (2009, p.33) definem como: "O texto é visto como simples produto de uma codificação realizada pelo escritor a ser decodificado pelo leitor, bastando a ambos, para tanto, o conhecimento do código utilizado." O foco no leitor para KOCH \& ELIAS (2009, p.33) pode ser entendido da seguinte forma: "A escrita, é entendida como uma atividade por meio da qual aquele que escreve expressa seu pensamento, suas intenções, sem levar em conta as experiências e os conhecimentos do leitor ou a interação que envolve esse processo." A terceira forma de conceber a leitura envolve escritor e leitor numa via de mão dupla onde quem escreve deve fazê-lo tendo em vista o conhecimento do leitor, assim a comunicação acontece a partir do conhecimento comum de ambos sobre o tema.

Entendemos, pois, a escrita como atividade de produção textual (TORRACE \& GALBRAITH, 1999) que se realiza, evidentemente, com base nos elementos linguísticos e na sua forma de organização, mas requer, no interior do evento comunicativo, a mobilização de um vasto conjunto de conhecimentos de escritor, o que inclui também o que esse pressupõe ser do conhecimento do leitor ou do que é compartilhado por ambos.

(KOCH \& ELIAS, 2009, p.35)

Durante a vida, aprendemos a ler e escrever e convivemos diariamente com textos, o que nos permite desenvolver a capacidade de leitura e escrita. A interação entre escritor e leitor tornase importante no processo de leitura, pois permite que haja uma troca de informações entre as partes envolvidas.

“A leitura é o processo mediante o qual se compreende a linguagem escrita (...)

HOLOS, Ano 27, Vol 5 
para ler necessitamos, simultaneamente, manejar com destreza as habilidades de decodificação e aportar ao texto nossos objetivos, ideias e experiências prévias; precisamos envolver em um processo de previsão e inferência contínua, que se apoia na informação proporcionada pelo texto e na nossa própria bagagem, e em um processo que permita encontrar evidência ou rejeitar as previsões e inferências antes mencionadas." (SOLÉ, 1998, p.23)

A leitura é importante para a compreensão da escrita e depende da concepção de quem lê, pois ela dá sentido ao texto. Para GONÇALVES (2010, p.04), "O leitor é um ser ativo, que interpreta o mundo a partir de fatores que dependem de sua intenção em relação ao que lê, dos valores e do conhecimento que traz, do tempo e da sociedade que vive." Assim, o leitor poderá interpretar o texto de acordo com seus conhecimentos e este poderá assumir valores diferentes daqueles que o escritor desejava transmitir.

"Os textos que lemos também são diferentes e oferecem diferentes possibilidades e limitações para a transmissão de informação escrita (...) as diferentes estruturas do texto impõem restrições à forma em que se organiza a informação escrita, o que obriga a conhecê-las, mesmo que intuitivamente, para se compreender esta informação de forma adequada." (SOLÉ, 1998, p.22)

Como vimos, a leitura é uma atividade de compreensão e interpretação daquilo que se lê, para que isso seja possível, recorremos às estratégias de leitura que auxilia na construção de sentido do texto. Essas estratégias permitem que enquanto a leitura esteja sendo feita, o leitor analise o que está sendo lido e a partir do conhecimento prévio este possa selecionar, antecipar, inferir e verificar as informações contidas no texto para que se construa um sentido.

Durante a leitura as antecipações serão levantadas e depois confirmadas ou rejeitadas. Serão, enfim, sempre testadas no movimento da leitura, a partir de conhecimentos que estão em nossa memória. (...) Esta antecipação de informações e as inferências decorrentes delas servirão de base para a compreensão do texto, verificando, testando as nossas hipóteses, exercitando, assim, a autorregulação do próprio processo de leitura. (GONÇALVES, 2010, p.09)

Na modalidade à distância, o aluno deve assumir uma postura autônoma e a leitura e a escrita estão presentes em todas as formas de comunicação/interação entre professor/tutor e aluno, por isso, essas estratégias são fundamentais para que o processo de leitura e, consequentemente, a escrita sejam desenvolvidas de maneira eficiente.

A Educação a Distância, é uma modalidade antiga que incorporou os mais variados meios na busca de estabelecer uma comunicação cada vez mais eficiente e eficaz. Nas últimas décadas com o avanço das Tecnologias da Informação de Comunicação, ampliaram-se bastante as formas de operar essa comunicação. (MARIZ, 2010, p.09) 
Apesar dos avanços tecnológicos, o material didático, que pode ser impresso ou em meio digital ainda é o principal responsável na transmissão de informação e porta-voz do que o professor pretende passar para o aluno e torna-se eficiente de acordo com sua utilização e, por isso, deve ser apresentado de forma que o aluno desperte interesse e sinta-se motivado a estudar, ou seja, o autor deve colocar-se no lugar do leitor para que ocorra uma satisfatória interação.

\footnotetext{
O material didático tem que motivar os alunos através do estabelecimento de um diálogo permanente, da proposição de atividades que instiguem a busca pela descoberta e pela pesquisa e que estejam relacionadas com o contexto de vida do aluno; tem que ser atraente e proporcionar ao aluno o prazer de manuseá-lo. Na EaD, como já vimos, o material didático é o substituto direto do professor. (MARIZ, 2010, p.09)
}

O material didático bem elaborado, interessante e em uma linguagem dinâmica de compreensão simples é indiscutivelmente uma forma eficiente de potencializar o processo de ensino aprendizagem. É o elo entre o professor e o aluno, principalmente nas relações existentes no ensino a distância, é nele que a informação ou o conhecimento empírico se transforma em conhecimento sistematizado ou cientifico. Deve ser atraente e conter uma linguagem clara e direta para que a compreensão seja imediata, sendo elaborado de forma a dar impressão de que o professor/tutor está presente, mas este deve apenas esclarecer dúvidas que surgirão ao longo do processo de ensino e aprendizagem.

\section{EDUCAÇÃO A DISTÂNCIA E OS PROCESSOS DE LEITURA E ESCRITA}

A modalidade a distância, por ser algo ainda novo para muitos de nós estudantes, pode levar um tempo para que todos os alunos se adaptem às mudanças decorrentes da transição do ensino presencial para o ensino a distância. No primeiro, a comunicação entre professor e aluno se dá de forma imediata, as aulas são presenciais e o professor explica o conteúdo das aulas e tira as dúvidas da turma à medida que as dúvidas vão aparecendo. No segundo, as aulas são mediadas por apostilas e textos disponibilizados na plataforma por cada professor e cabe ao aluno acessar esse material. A leitura e interpretação do conteúdo de cada aula deve ser feita, em princípio, exclusivamente pelo aluno. Suas dúvidas deverão ser expostas nos fóruns da plataforma e aguardar até 48 horas para obter uma resposta que pode ser satisfatória ou não, dependendo da interpretação tanto do professor/tutor que lê a pergunta e a responde quanto do aluno que expõe suas dificuldades e aguarda um retorno. Esse processo de interação é muito importante para as partes envolvidas e dela depende o êxito ou fracasso da comunicação.

Segundo SOLÉ (1998, p.22) "O significado que um escrito tem para o leitor não é uma tradução ou réplica do significado que o autor quis lhe dar, mas uma construção que envolve o texto, os conhecimentos prévios do leitor que o aborda e seus objetivos." 
Essa comunicação entre professor/tutor e aluno pode sofrer interferência, uma vez que quem escreve deseja passar uma mensagem que nem sempre é compreendida da maneira como deveria por quem lê.

O como dizer o que se quer dizer é revelador de que a escrita é um processo que envolve escolha de um gênero textual em consonância com as práticas sociais, seleção, organização e revisão das ideias para os ajustes/reajustes necessários, tendo em vista a eficiência e a eficácia da comunicação. (KOCH \& ELIAS, 2009, p.36)

$\mathrm{Na}$ educação tradicional, o material didático é utilizado pelo professor como apoio enquanto na educação a distância este se apresenta como substituto do professor e, portanto, torna-se indispensável para o aluno que deverá ter uma compreensão crítica do que está sendo estudado.

Na Educação a Distância, o material didático substitui a aula tradicional. É através dele que o aluno estabelece contato com o conhecimento. É como se ele fosse o substituto do professor. Por isso, a sua produção para a EaD deve levar em conta aspectos de interatividade que, por não poderem se realizar no mesmo modelo da educação presencial, precisam estar presentes no material didático. (MARIZ, 2010, p.06)

$\mathrm{Na}$ EaD a interação entre alunos, professores, tutores e colegas se dá geralmente por meio de comunicação assíncrona, que segundo $\operatorname{MARIZ}(2010$, p.12), "é aquela em que a interação não se dá em tempo real, como por exemplo, através de cartas, e-mails, chats, fax, mensagens no celular, etc." Outras formas de comunicação também são utilizadas como: blogs, fóruns, sites, teleconferência e outras tecnologias disponíveis, sejam elas em tempo real ou não e as inovações tecnológicas vêm para auxiliar o processo de ensino-aprendizagem, devendo ser utilizadas de maneira adequada com o objetivo de auxiliar o desenvolvimento das atividades.

O processo de leitura e compreensão de um texto requer uma série de mecanismos que auxiliam na construção de sentido. Mecanismos que levam em consideração não só os aspectos intrínsecos ao texto, mas os conhecimentos de mundo do leitor. Nesse processo, é de fundamental importância a compreensão do contexto em que aquele texto foi elaborado e está em uso. O leitor processa essas informações automaticamente enquanto participa do processo de construção dos sentidos do texto e, para isso, utiliza uma série de mecanismos. Esse processo, no entanto, implica uma maior ou menor velocidade de compreensão do texto. Um texto com poucos obstáculos permite uma leitura rápida de sentido tão imediato que quase se perde o controle consciente de sua compreensão. (GONÇALVES \& CAVALCANTE, 2010, p.08)

As estratégias de leitura e o desenvolvimento da escrita tornam-se indispensáveis no processo de aprendizagem e no Ensino a Distância elas se transformam em aliadas do aluno, contribuindo para um melhor entendimento do material didático. 
Qual o papel do leitor enquanto construtor de sentido? Espera-se que ele processe, critique, contradiga ou avalie a informação que tem diante de si, e, para tanto, lance mão de critérios como seleção, antecipação, inferência e verificação para realizar bem o ato da leitura. (GONÇALVES, 2010, p.09)

Diante da necessidade de analisar e entender como a leitura e a escrita contribuem para o aprendizado da língua espanhola no ensino a distância, o estudo sobre as estratégias de leitura tem como objetivo responder à seguinte indagação:

"Qual a importância do desenvolvimento de estratégias de leitura para a aprendizagem da língua espanhola?"

Objetivamos com este estudo identificar a importância das estratégias de leitura na aprendizagem da língua espanhola, como objetivos específicos buscamos entender como o desenvolvimento de estratégias de leitura contribuem para a aprendizagem; analisar a importância da interpretação de textos no processo de aprendizagem; identificar, a partir das mensagens postadas nos fóruns pelos alunos, como a escrita contribui para o processo de aprendizagem e compreender como a escrita é importante no processo de comunicação entre alunos e professores/tutores na modalidade EaD;

\section{O UNIVERSO DA PESQUISA: EM BUSCA DO MÉTODO}

A pesquisa está sendo realizada através algumas postagens da Plataforma Moodle utilizada no curso de Licenciatura em Letras Espanhol do IFRN na modalidade a distância do polo de Natal. O universo dessa pesquisa é composto por alguns alunos do polo de natal que publicaram postagens nos fóruns da disciplina de Língua Portuguesa na plataforma Moodle.

O trabalho define-se como sendo uma pesquisa de campo de natureza descritiva. Seu objetivo foi aprofundar o conhecimento da realidade estudada, através da observação, análise e correlação de fatos tentando não manipulá-los a partir de uma análise sobre as dificuldades encontradas pelos alunos do curso de Licenciatura em Letras Espanhol do IFRN na modalidade a distância do polo de Natal.

Na pesquisa de campo, o objeto/fonte é abordado em seu meio ambiente próprio. A coleta de dados é feita nas condições naturais em que os fenômenos ocorrem, sendo assim diretamente observados, sem intervenção e manuseio por parte do pesquisador. Abrange desde os levantamentos (surveys), que são mais descritivos, até estudos mais analíticos.(SEVERINO, 2008, p.123) 
A pesquisa é realizada por meio de observação participante natural, pois a autora faz parte do grupo objeto da investigação.

A observação ajuda o pesquisador na identificação e obtenção de provas a respeito de objetivos sobre os quais os indivíduos não tem consciência, mas que orientam seu comportamento. Desempenha papel importante nos processos observacionais, no contexto da descoberta, e obriga o investigador a um contato mais direto com a realidade. É o ponto de partida da investigação social.(LAKATOS \& MARCONI 2004, p.275)

Sobre a observação natural, LAKATOS E MARCONI (2004, p.275) dizem o seguinte: "ocorre quando o indivíduo observador pertence à mesma comunidade ou grupo investigado."

A pesquisa parte da obtenção de dados primários e secundários coletados de diversas fontes.

Os dados primários deste estudo foram obtidos a partir de informações da autora sobre sua experiência na modalidade EaD.

Os dados secundários deste estudo foram obtidos por meio de pesquisas bibliográficas, internet, postagens dos alunos nos fóruns da plataforma Moodle, material didático do curso e atividades enviadas pela autora para a disciplina de Língua Portuguesa.

\section{PRIMEIRAS ANÁLISES}

Os dados obtidos pela pesquisadora foram analisados de acordo com o conceito de análise de conteúdo proposto por Martins (2002, p. 55);

Os dados e as informações deverão ser analisados visando à solução do problema de pesquisa proposto e o alcance dos objetivos pretendidos. Nesta fase, o pesquisador irá classificar os dados, dando-lhes ordem ou colocando-os nas diversas categorias, segundo critérios que facilitem a análise e interpretação em face dos objetivos da pesquisa.

Segundo LAKATOS \& MARCONI (2001, p.167-168) "Análise é a tentativa de evidenciar as relações existentes entre o fenômeno estudado e outros fatores. Interpretação é a atividade intelectual que procura dar um significado mais amplo às respostas, vinculando-as a outros conhecimentos".

Os dados foram analisados qualitativamente, de acordo com a proposta de análise de conteúdo de Martins (2002), onde "os dados devem ser analisados de forma a solucionar o problema pesquisado e alcançar os objetivos pretendidos". 
Na modalidade de Ensino a Distância, a quantidade de leitura que se deve fazer é relativamente maior do que em relação ao ensino presencial, uma vez que toda forma de comunicação é realizada através de textos. A leitura e compreensão do material didático é também de responsabilidade do aluno que deve desenvolver mecanismos de leitura que o auxilie, nesse momento, as estratégias de leitura tornam-se presentes em grande parte do processo, pois são elas que darão suporte ao aluno em suas atividades.

$\mathrm{Na} \mathrm{EaD}$, a utilização dessas estratégias torna-se necessária, pois a figura do professor que explica o conteúdo não estará a disposição do aluno, este apenas poderá responder algumas dúvidas que serão respondidas em forma de texto. Mais uma vez, o aluno deverá recorrer às estratégias de leitura para entender a resposta às suas indagações. É um processo contínuo e por isso necessita que o aluno tenha autonomia e que seja capaz de utilizar os mecanismos de compreensão de leitura a seu favor, sendo proativo na construção de sentido.

Para compreender um texto, a partir de sua leitura, o aluno fará inicialmente a seleção das mensagens contidas no texto, para depois fazer as antecipações e levantar hipóteses acerca do que está sendo lido, que poderão ser confirmadas ou não no decorrer da leitura. Nesse momento, serão feitas as inferências, realizando conexões indiretas entre o que se conhece do tema e o texto lido que serão a base para sua compreensão. Logo após, as verificações testarão as hipóteses. Esse processo possibilitará uma boa leitura e compreensão do texto. Se essas estratégias não forem corretamente utilizadas, pode comprometer o sucesso da leitura e a interação não ocorrerá satisfatoriamente.

Podemos entender que a interpretação do que foi lido é de responsabilidade do leitor e o uso dessas estratégias contribuem para que a mensagem do autor seja entendida de forma adequada. Assim, as estratégias de leitura contribuem para a formação de leitores autônomos, que possam aprender através da leitura e sejam capazes de utilizar o conhecimento adquirido anteriormente para a compreensão de textos.

A partir da análise das postagens dos alunos nos fóruns de Língua Portuguesa na Plataforma Moodle, observa-se que, em sua maioria, os alunos podem não estar fazendo uso adequado das estratégias de leitura. A maioria das postagens estão relacionadas a problemas de compreensão do conteúdo das aulas e questões sobre as atividades. Alguns alunos não estão interpretando corretamente as informações e definições de maneira clara. Muitas vezes, as dúvidas poderiam ser esclarecidas apenas com uma leitura do material se o aluno buscar desenvolver as estratégias de leitura, como podemos observar na postagem do Aluno3 e na resposta da professora:

\section{“Duvidas atividade 09}

por Aluno3 - quinta, 14 outubro 2010, 09:39 
Alguem pode me explicar o conteudo da aula 09? Seguencia descritiva e seguencia narrativa... estou com duvida de como identificar cada uma.

aguardo com urgencia.

\section{Re: Duvidas atividade 09}

por Professora - quinta, 14 outubro 2010, 18:48

Querido Aluno3,

Releia o material com calma, pois o mesmo apresenta muitas informações que te ajudarão a identificar as duas sequências. Um bom exercício é você, a partir do material, elaborar um quadro no qual colocará as duas sequências e o que caracteriza cada uma delas. Leia também o quadro sobre sequência textuais presentes na aula 08, o mesmo apresenta com detalhes as características de cada uma delas.

Abraços, estou à disposição.

Professora"

A comunicação entre professores/tutores e alunos não é imediata nesta modalidade, ou seja, não é on-line, pois professores e tutores respondem de forma assíncrona ${ }^{1}$ e o processo de escrita assume o papel central na comunicação entre eles. É por meio da escrita que os alunos podem expressar suas dúvidas e dificuldades e os professores/tutores respondem a essas dúvidas. No entanto, quando as dúvidas não são respondidas imediatamente, a necessidade de realizar a escrita de forma que promova melhor interação é fundamental, como podemos observar nas datas e horários da conversa a seguir:

\section{“Re: Duvidas atividade 09 \\ por Aluno4 - segunda, 18 outubro 2010, 19:46 \\ Quanto a fazer um texto descritivo a partir do texto já existente.}

Estou com duvida com relação ao que posso descrever, quais

1 Comunicação Assíncrona é segundo MARIZ (2010, p.12), "aquela em que a interação não se dá em tempo real, como por exemplo, através de cartas, e-mails, chats, fax, mensagens no celular, etc." 
palavras utilizar?

\title{
Re: Duvidas atividade 09
}

por Tutor - terça, 19 outubro 2010, 08:41

Caro Aluno4, observe que o texto já existente é uma fábula. A fábula é um gênero textual

que transmite um ensinamento e cujos personagens são animais personificados (ex. A

Cigarra e a Formiga, O Lobo e o Cordeiro etc.). Apresenta como sequência predominante a narrativa, pois relata um fato ou uma série de acontecimentos, no qual se incluem personagens e suas ações, situando-os no tempo e no espaço. Quanto à questão solicitada, ela pede que você elabore, a partir do texto narrativo A Cigarra e a Formiga, uma sequência descritiva. Veja um exemplo de seq. descritiva: "O professor era gordo, grande e silencioso, de ombros contraídos. Em vez de nó na garganta, tinha ombros contraídos. Usava paletó curto demais, óculos sem aro, com um fio de ouro encimando o nariz grosso e romano. E eu era atraída por ele." (Clarice Lispector)

Observe que como na seq. descritiva se procura retratar um objeto (pessoa, coisa, animal, paisagem), há um detalhamento de aspectos, características e atributos.

Espero ter ajudado. Qualquer dúvida, entre em contato.

\author{
Re: Duvidas atividade 09 \\ por Aluno5 - quinta, 21 outubro 2010, 18:06 \\ Ajudou bastante! \\ Grata!"
}

A importância de escrever de maneira que outra pessoa entenda é fundamental num processo de comunicação. Às vezes, o autor não se coloca no lugar do leitor e isso dificulta o entendimento do texto. Ou seja, ao escrever, a pessoa deve transmitir a mensagem que deseja passar de uma maneira compreensível para quem a lê. Deve preocupar-se com a linguagem 
utilizada, construir frases concisas e ser o mais claro possível. Para exemplificar, vamos analisar uma postagem feita por um aluno em um fórum de dúvidas:

\section{“duvidas !!!!!!!!! \\ por Aluno1 - sábado, 6 novembro 2010, 11:27}

ola professora nao sei se é só eu se for desconsidere esta duvida. pois eu venho tentando descobrir oq se pede em cada atividade como na prova presencial que muitos protestaram.

exemplos $=$

tem uma classe 15 que pede :

pesquise literatura -= nao sei oq procurar

pesquise poemas que vc mais goste $=$ esta ate que entendi pouco

pois acho que temos que advinhar oq se pede realmente em cada atividade ...obg.."

Observando a postagem do Aluno1, não fica claro o que ele quer dizer, pois se expressou de uma forma quase incompreensível. Não é possível identificar qual é sua dúvida porque não a expõe de maneira que promova compreensão. Por se tratar de um ambiente acadêmico, a linguagem utilizada está inadequada, além das questões de ortografia e de concordância que podem comprometer a leitura, a construção das frases é confusa. Assim, identificamos que o Aluno1 não teve a preocupação de se colocar no lugar do leitor, ou seja, escrever de uma forma clara e concisa o seu problema para que a professora pudesse compreender suas dúvidas e dirimílas.

Diante desta situação, a professora que não compreendeu qual era a dúvida do Aluno1, necessitou enviar uma mensagem tentando obter mais informações a respeito do questionamento e poder dar uma resposta. Com isso, o Aluno1 só teve sua pergunta respondida após esclarecer o que tinha escrito, o que poderia ter sido evitado se ele tivesse tido a preocupação de escrever de uma forma mais clara e compreensível.

Percebe-se pela comunicação realizada pela plataforma Moodle que nem sempre os autores se colocam no lugar dos leitores e a comunicação fica prejudicada, pois o leitor ao invés de poder responder imediatamente a dúvida do escritor tem que enviar-lhe outra mensagem pedindo que se expresse melhor. Nesse processo, percebemos que a interação escritor-leitor apresenta diversos aspectos que a comprometem, entre os quais, a dificuldade de colocar-se no lugar do 
leitor para que o mesmo compreenda o seu texto nos processos de comunicação assíncrona.

\section{CONSIDERAÇÕES FINAIS}

A partir da análise das postagens dos alunos e das atividades enviadas pela autora, percebe-se que alguns de nós ainda não fazemos uso adequado da leitura e escrita, o que pode estar dificultando o processo de aprendizagem. No entanto, a interação constante entre escritorleitor, que é uma característica fundamental do ensino a distância, promove o exercício dos processos de leitura e escrita e suscita a busca por estratégias para desenvolvê-los. Entende-se que é pertinente abordar com mais profundidade como o desenvolvimento de estratégias de leitura, apresentadas pelos autores citados e parte dos conteúdos da disciplina de Língua Portuguesa pode contribuir para melhorar a leitura e compreensão de textos e minimizar as dificuldades encontradas pelos alunos do curso de licenciatura em língua espanhola a distância do IFRN/UAB. Os estudos aqui desenvolvidos suscitaram a busca por uma investigação mais aprofundada e culminou na construção do projeto de pesquisa $O$ desenvolvimento de estratégias de leitura para a aprendizagem de espanhol a distância, desenvolvido atualmente pelo grupo de pesquisa Capacitação de Recursos Humanos no uso de tecnologias da Informação e Comunicação aplicadas a Educação, no qual a autora é bolsista de iniciação científica. A pesquisa está sendo desenvolvida tomando como base os resultados obtidos neste estudo e que servem de apoio na elaboração dos instrumentos de coleta de dados.

\section{REFERÊNCIAS BIBLIOGRÁFICAS}

1. GIL, Antonio Carlos. Como elaborar projetos de pesquisa. 4. ed. São Paulo: Atlas, 2004.

2. GONÇALVES, Rousiene Silva. Língua Portuguesa I: texto e sentido. Aula 02. Natal, 2010.

3. GONÇALVES, Rousiene Silva; CAVALCANTE, llane Ferreira. Língua Portuguesa I: estratégias utilizadas para a compreensão e interpretação de textos. Aula 03. Natal, 2010.

4. KOCH, Ingedore Villaça; ELIAS, Vanda Maria. Ler e compreender: os sentidos do texto. São Paulo: Contexto, 2006

5. _ـ Ler e escrever: estratégias de leitura e produção textual. São Paulo: Contexto, 2010.

6. LAKATOS, Eva Maria; MARCONI, Marina de Andrade. Fundamentos de metodologia científica. 4. ed. - São Paulo: Atlas, 2001. 
7. Metodologia científica. 4. ed. São Paulo: Atlas, 2004.

8. MARIZ, Liane Trindade. Educação a distância: bases conceituais e evolução histórica. Aula 02. Natal, 2010.

9. __ Professores e alunos de educação a distância. Aula 04. Natal, 2010.

10. Material didático na educação a distância: natureza, tipologia e elemento. Aula 05. Natal, 2010.

11. . Mídias e ferramentas na educação a distância. Aula 06. Natal, 2010.

12. A tutoria na aprendizagem a distância: interatividade e afetividade. Aula 08. Natal, 2010.

13. MARTINS, Gilberto de Andrade. Manual para elaboração de monografias e dissertações. 3 . ed. São Paulo: Atlas, 2002.

14. SEVERINO, Antonio Joaquim. Metodologia do trabalho científico. 23. ed. rev. e atual. São Paulo: Cortez, 2008.

15. SOLÉ, Isabel. Estratégias de leitura. Porto Alegre: Artmed, 1998. 